\title{
Bridging Education, Research and Innovation: The Pivotal Role of Doctoral Training [Overview Paper]
}

\author{
Marzia Foroni
}

Given its pivotal position, Doctoral programmes have been looked at from two main angles: education and research. Depending on the historical development and the main features of the various academic communities in Europe, one of the two points of view might prevail.

In some context, what prevails is their integration in the educational path, where talented students prove themselves in the frontier of knowledge by creating innovative and original knowledge. In the process, they are expected to refine their competences in analyzing new knowledge and in critical thinking, in presenting it to different kinds of audiences, and can be expected to be able to promote technological, social and cultural advancement in a knowledge based society. They are expected to develop their generic skills and competences at the highest level in a formal education context by confronting themselves with researching new knowledge. It is also understood that, within the Bologna context, the principles, policies and tools that apply to the previous level of higher education should also apply to Doctoral programmes, while taking into account the specificities of its research-based approach. Both the Overarching Framework of Qualifications for the European Higher Education Area and the European Qualification Framework include these programmes in their highest level, respectively level three and level eight.

In other context, Doctoral training is seen as more embedded in research: Doctoral graduates are trained in producing new knowledge, are fully autonomous in developing it further in the realm that suits them best, being it the academia or the non-academic world. They should be embedded in stimulating research environment and involved in major research projects, with international profile.

M. Foroni $(\bowtie)$

Ministry of Education, Universities and Research, Rome, Italy

e-mail: marzia.foroni@gmail.com

(C) The Author(s) 2015

A. Curaj et al. (eds.), The European Higher Education Area,

DOI 10.1007/978-3-319-20877-0_34 
In recent years, partly induced by the European political strategies, mainly the Bologna Process and the construction of the European Research Area, and partly on the basis of national priorities, all European countries have revised their strategies on Doctoral education. ${ }^{1}$ As efficiently summarized by EHEA Ministers in Bucharest, amongst the priorities for political initiative for the periods 2012-2015 in the Communiqué of 2012, the main aim of policies in Doctoral education was to "promote quality, transparency, employability and mobility in the third cycle".

Where the initiative has not been taken by politics, however, higher education Institutions have questioned and improved the quality of Doctoral education on their own initiative. The majority of Institutions have implemented part of the Salzburg Principles promoted by the European University Association or have joined other bottom-up initiatives like the Tuning recommendations on how to develop Doctoral programmes. Institutions begun to see differently the relationship between themselves and the doctoral candidate. The commitment of both parties, roles and expectations should be clarified and approved in advance in order to make the best use of all available competence and institutional assets.

Looking at the various reform initiatives, some common elements can be found:

- an increased attention on the quality of supervision;

- an increase in the international dimension of programmes, with more Doctoral candidates and supervisors mobility, and more international cooperation through joint programmes;

- an increase in interdisciplinarity;

- an increase in collaboration with the non-academic labour market, with more focus on industry, in all the forms that it might take place.

The role of supervisors for the successful completion of a Doctoral programme and of a research project is being recognized as increasingly important. They help candidates in the achievement of a broader set of competencies and in the development of their research careers. To accomplish this role, they should be adequately trained and supported by Institutions. In many cases, it can be seen a move from individual, one to one, supervision approach to a more team-based approach where one or a group of candidates interacts with a team of supervisors from different research backgrounds.

Concerning the increase in internationalization, in interdisciplinarity and in collaboration with the non-academic world, a mean to reach these ends has been the creation of Doctoral Schools and, more generally, a structured approach to Doctoral programmes. Structured doctoral training leads to clearer governance structures and policies at the institutional level concerning admission, quality assurance, assessment, supervision. In parallel, sometimes as interlinked strategy, institutions embedded training activities in the discipline or in transferable skills leading to

\footnotetext{
${ }^{1}$ Depending on the context, Doctoral programmes can be referred to as "Doctoral education" or as "Doctoral training", in one case underlining more the learning process beneath and in the other the research approach. For the purpose of the discussion, we interpret both terms as equivalent.
} 
structured Doctoral programmes, composed by pre-defined training activities, classes, experiences in teaching to students from previous cycles or internships in enterprises.

The premise on which national and institutional strategies on Doctoral education are developed is that societal and economic innovation can be created only with the full realization of the potential of Doctoral graduates. This is even more relevant as all European countries are facing big challenges in the economy, like the emergence to recover from the economic crisis, in society, like the raise of increasingly old and diverse societies, in the environment, and so on. Consequently, Doctoral graduates should be trained adequately to achieve a variety of competencies that were not considered as focal before.

Solving the inefficiencies, improve processes and production, and encourage new generators of income depends on innovation of the labour market and on the fact that it benefits from the contribution of the new generation of Doctorate holders. Innovation, and inclusion of Doctoral graduates, is also needed in all sectors of public administration, where old structures are called upon to face fast evolving challenges and in academia.

While Doctoral graduates and higher Education Institutions are asked to ensure that newly developed knowledge is transferred to society, the surrounding world should ensure that they are fully welcome and integrated. Therefore, policy initiatives launched at the national level all include elements on transfer of innovation, support for start-ups and incentives to develop further university-business cooperation.

Indeed, if one would have to search for any innovative element in Doctoral training policy development in past years, that would be a steadily stronger attention to what Doctoral graduates know and are able to do and to what they should be empowered to do.

This is true not only for the design and delivery of programmes or for the development of a research project. Attention to the competences achieved is incentivized also by a renewal of the evaluation criteria used for programmes and for their research results. Doctoral candidates are often too narrowly evaluated and there are several unintended negative consequences of the use of present standards for assessing candidates. There is a need for internationally agreed standards to evaluate/compare the competences achieved by doctoral students, based on the expected outcomes of doctoral programmes, be they oriented more towards academic careers or careers outside the academia.

As European citizens and academics, we can say that the challenges mentioned have a European dimension and that solutions should be found at the European level. The construction of the European Higher Education Area and of the European Research Area are two tentative solutions on the table.

The successful achievement of these supra-national policy initiatives depends on the willingness of all parties involved to further insist on their synergies. In the European Higher Education Area, the connection between the realm of higher education and research has always been recognized, but never looked further than from the point of view of education. In the European Research Area, geographically 
smaller and with a different governance structure, the field of higher education has never been taken into consideration and the issue of Doctoral training has been considered only as the first step into research.

Last but not the least, to mirror the knowledge triangle "Education, research and innovation", each of these fora should concentrate more on the "innovation" angle. Structural and policy reform in higher education should also conduct to new generations of graduates capable to bring innovation into society. The products of increased cooperation in research at the European level should also look at how we can face the grand challenges of modern societies. This concept of looking at what is beyond the reproduction of knowledge and the creation of new knowledge by taking into consideration what happens outside of academia and try to innovate it, is closely connected with the wider debate on the "third mission" of Institutions.

The papers selected for publication on the topic "Education, research and innovation" look deeper into some of these aspects.

Starting from the overview of what happens at the European level, Nicola Vittorio will discuss the implementation of European policies in different European countries, with a specific focus on the Italian case, and the main outcomes to improve quality, internationalization, transparency and employability in the Third cycle, of the ad hoc working group on the Third cycled established by the Bologna Follow up Group for the period 2012-2015. Following the complementarity approach of the Tuning initiative with the Bologna Process, Ann Katherine Isaacs will bring the voice of those in Institutions with hand-on knowledge in teaching and learning and present their recommendations to develop competence-based Doctoral programmes. Leaving aside the "structural" approach that characterizes European policy initiatives, Linda Evans will present a different reference model on how Doctoral programmes should be developed, starting from the nature of researcher development and its professional characteristics. John Peacock and Filomena Parada, thanks to the broad data collected by Eurodoc on Doctoral candidates and junior researchers, will present the views of candidates on how to best organize and structure Doctoral training and the perceptions of candidates on several aspects of Doctoral training, such as the type of supervision, training opportunities, skills and expectations for successful careers. Finally, Alexandru Nicolin and Florin Buzatu will discuss on the positive impact of exposing graduate students to forefront achievements in scientific research, to international experiences and to interdisciplinarity. In addition, they will discuss the impact of present practices in the evaluation of research as incentivizing (or, rather, not) internationalization and interdisciplinarity at the Doctoral level in Romania.

Open Access This chapter is distributed under the terms of the Creative Commons Attribution Noncommercial License, which permits any noncommercial use, distribution, and reproduction in any medium, provided the original author(s) and source are credited. 